\title{
Efeito da Utra-Estabilização da Zeolita Y no Hidro-Craqueamento de Óleo de Soja Bruto $^{1}$
}

Cassio Henrique Zandonai², Patrícia Hissae Yassue Cordeiro², Sibele Berenice Castellã Pergher $^{3}$, Nadia Regina Camargo Fernandes Machado ${ }^{4}$

${ }^{1}$ Aceito para publicação no $3^{\circ}$ trimestre de 2014

2 Professores Assistentes na Universidade Estadual de Maringá- UEM, chzandonai@gmail.com; patrícia.yassue@gmail.com

3 Professora Adjunto na Universidade Federal do Rio Grande do Norte, sibelepergher@gmail.com

${ }^{4}$ Professora Associada na Universidade Estadual de Maringá- UEM, nadia@ deq.uem.br

\section{RESUMO}

Como alternativa ao consumo de combustíveis fósseis, há a possibilidade de se produzir combustíveis renováveis a partir de biomassa, como do óleo de soja. Pelo processo de hidrocraqueamento catalítico se obtém combustíveis e insumos petroquímicos a partir de triglicerídeos. Neste trabalho foram utilizados os catalisadores NaY e USY, com diferentes quantidades de $\mathrm{Si}$ e $\mathrm{Al}$ em suas estruturas e diferentes cátions de compensação, o que levou uma diferença da acidez dos seus sítios ativos, observadas por ressonância magnética nuclear de ${ }^{29} \mathrm{Si}$ e dessorção à temperatura programada (DTP), respectivamente. A reação de hidrocraqueamento foi realizado em reator de leito fixo e o produto foi analisado após trinta minutos de reação por cromatografia a gás com espectrometria de massas. Obteve-se elevada seletividade a hidrocarbonetos, principalmente gasosos, e uma grande diferença entre os produtos líquidos dos dois catalisadores utilizados. Foi observada uma pequena quantidade de ácidos orgânicos no produto final.

\section{PALAVRAS-CHAVE}

Catálise heterogênea, biocombustíveis, renovável. 


\title{
EFFECT OF ULTRA-STABILIZATION IN Y ZEOLITE IN HYDROCRACKING OF CRUDE SOYBEAN OIL
}

\begin{abstract}
As an alternative to fossil fuel consumption, there is the possibility of producing fuels from renewable biomass such as soybean oil. By catalytic hydrocracking process, fuels and petrochemical feedstock from triglycerides can be produced. In this work the NaY and USY catalysts with different amounts of $\mathrm{Si}$ and $\mathrm{Al}$ in their structures and different exchanged cations, prompting a difference in the acidity of their active sites, observed by magnetic resonance 29Si and temperature programmed desorption were used (DTP), respectively. The hydrocracking process was carried out in a fixed bed reactor, and the product was analyzed after thirty minutes of reaction by gas chromatography with mass spectral analyzes. It was obtained high selectivity to hydrocarbons, especially gas, and a large difference among the products of the two catalysts used. A small amount of organic acids in the final product was observed.
\end{abstract}

\section{KEYWORDS}

Heterogeneous catalysis, biofuels, renewable.

\section{INTRODUÇÃO}

A utilização de combustíveis de origem fóssil vem causando diversos desequilíbrios ambientais e gerando custos de forma indireta devido à poluição. Como alternativa a esses combustíveis é considerada inclusive a conversão de óleos de origem vegetal em combustíveis renováveis. A rota de craqueamento termocatalítico de óleo vegetal é capaz de gerar combustíveis com estrutura química e propriedades físicas iguais às dos combustíveis do petróleo, e com teor desprezível de enxofre, nitrogênio e metais pesados (TIAN et al., 2008).

Esse processo objetiva a obtenção de hidrocarbonetos na faixa dos combustíveis a partir do óleo vegetal. Para isso ocorrem dois processos, a desoxigenação dos compostos e a fragmentação da cadeia carbônica dos mesmos. O primeiro estágio do processo consiste na decomposição do triglicerídeo. Esse processo se dá por efeitos térmicos e pela interação com 
os sítios ácidos de um sólido, onde as ligações entre os oxigênios do ácido graxo e os carbonos do glicerídeo são quebradas (DUPAIN et al., 2007), gerando ácidos graxos livres e uma molécula de propano insaturada.

A desoxigenação dos ácidos orgânicos pode ocorrer por duas principais vias: a descarboxilação e a hidrodexogenação. A descarboxilação é o processo onde ocorre a cisão- $\alpha$ da ligação carbono-carbono da carboxila gerando uma molécula de dióxido de carbono e uma molécula de hidrocarboneto, essa com um número de carbono menor que do ácido original. A hidrodesoxigenação é o processo que ocorre em um meio rico em hidrogênio, onde os oxigênios da carboxila do ácido são atacados por esse, gerando duas moléculas de água e um hidrocarboneto com cadeia carbônica de mesmo tamanho que a do ácido original (YANG et al., 2013).

Os diversos óleos vegetais já estudados mostraram que o processo de craqueamento possui baixa sensibilidade quanto à matéria prima utilizada (TWAIQ et al., 2004). Nesse sentido há a possibilidade de se empregar óleos de baixo custo, como óleo vegetal não tratado, no processo de craqueamento, como o demostrado por Melero et al. (2010) que utilizaram óleo bruto de soja e de palma como aditivos da matéria prima no processo de craqueamento de petróleo pesado. Vários trabalhos descrevem a conversão de óleo de palma em hidrocarbonetos líquidos como o de (TWAIQ et al., 1999) onde foi craqueado óleo de palma em um microrreator, leito fixo, à pressão atmosférica, com temperatura variando de 350-450 ${ }^{\circ} \mathrm{C}$ e WHSV de 1 a $4 \mathrm{~h}^{-1}$. Os catalisadores utilizados foram HZSM-5, zeólita beta, USY, híbridos desses três catalisadores. O maior rendimento em gasolina foi obtido com a utilização do catalisador hibrido HZSM-5-USY.

O presente trabalho teve por objetivo explorar a aplicação das zeólitas USY e NAY no craqueamento catalítico de óleo vegetal experimentalmente, para avaliar a interferência do processo de ultraestabilização. Para isso foram realizados testes em laboratório, avaliando-se a alteração no perfil de produtos do processo.

\section{MATERIAIS E MÉTODOS}

\section{Testes Experimentais de Craqueamento}

Foi utilizado óleo de soja bruto, obtido junto à linha de produção, antes de ser degomado ou clarificado. Os testes experimentais foram realizados em microrreator tubular de leito fixo, com 4 góleo/h.g gat, realizando-se a ativação prévia do catalisador, sob fluxo de 
$40 \mathrm{~mL} / \mathrm{min}$ de nitrogênio durante uma hora a $500^{\circ} \mathrm{C}$. Conduziu-se a reação, sob $450^{\circ} \mathrm{C}$, com $40 \mathrm{~mL} / \mathrm{min}$ de hidrogênio e $1 \mathrm{~g}$ de catalisador, com diâmetro médio de partícula de $589 \mu \mathrm{m}$, durante $30 \mathrm{~min}$. A alimentação do óleo de soja foi feita com bomba tipo cilindro-pistão. Um condensador, à temperatura de fusão do gelo, realizou a separação dos produtos gasosos dos líquidos, estes com duas fases, uma aquosa e outra orgânica, onde a separação ocorreu via centrifugação a $1025 \mathrm{G}$ e $10 \mathrm{~min}$. O produto gasoso foi coletado com seringa na saída do condensador via septo.

\section{Análise dos Produtos do Craqueamento}

A fim de determinar a composição do produto gasoso se fez uso da cromatografia gasosa, com detector de condutividade térmica (TCD), equipado com uma coluna Porapak Q (3,15 mm de diâmetro e $90 \mathrm{~cm}$ de comprimento). Com injeção de misturas gasosas padrões de: $\mathrm{CO}, \mathrm{CO}_{2}, \mathrm{CH}_{4}, \mathrm{C}_{2} \mathrm{H}_{6}, \mathrm{C}_{2} \mathrm{H}_{4}, \mathrm{C}_{3} \mathrm{H}_{8}, \mathrm{C}_{3} \mathrm{H}_{6}, \mathrm{C}_{4} \mathrm{H}_{10}, \mathrm{~N}_{2}$ e $\mathrm{H}_{2} \mathrm{O}$ foi possível identificar os picos presentes no cromatograma. A programação da análise foi: $130{ }^{\circ} \mathrm{C}$ de temperatura inicial, mantida por $4 \mathrm{~min}$, seguida de uma rampa de $20^{\circ} \mathrm{C} / \mathrm{min}$ até $160^{\circ} \mathrm{C}$ mantida por $7 \mathrm{~min}$.

A determinação da composição do produto líquido foi realizada em cromatógrafo gasoso, CG-MS Thermo-Finigan, e em um sistema composto por um cromatógrafo em fase gasosa FOCUS GC (Thermo Electron), acoplado a um espectrômetro de massas DSQ II (Thermo Electron), equipado com coluna DB-5. A programação do forno foi: um patamar inicial $50^{\circ} \mathrm{C}$, mantida por um minuto; rampa de $4^{\circ} \mathrm{C} / \mathrm{min}$ até $250^{\circ} \mathrm{C}$, mantida por $10 \mathrm{~min}$, semelhante a Chen et. al. (2010). Os componentes foram identificados de acordo com a massa de seus íons na biblioteca do equipamento.

Pela presença de ácidos graxos, que têm a mesma polaridade que a fase da coluna cromatográfica, foi realizado um pré-tratamento da amostra. As amostras eram esterificadas através da metodologia descrita por Hartman e Lago (1973), que consiste em uma metilação por catálise ácida. Foi adicionado em um tubo de ensaio $100 \mathrm{mg}$ do produto líquido, em seguida adicionado $2 \mathrm{~mL}$ da solução hidróxido de sódio a $0,5 \mathrm{~mol} / \mathrm{l}$. O tubo foi aquecido em banho termostático a $90^{\circ} \mathrm{C}$ por 5 min e após um rápido resfriamento em água corrente, foi adicionado $3 \mathrm{~mL}$ do agente de esterificação $(33,33 \mathrm{~g}$ de cloreto de amônio e $50 \mathrm{~mL}$ de ácido sulfúrico em um litro de metanol). Foi realizado mais um aquecimento da amostra até $90^{\circ} \mathrm{C}$ por $3 \mathrm{~min}$, após o resfriamento foi adicionado $2 \mathrm{~mL}$ de solução saturada de cloreto de sódio, 
para separar as fases. Por fim foi adicionado $3 \mathrm{~mL}$ de solvente não presente na amostra, neste caso iso-pentano.

\section{Caracterização dos Catalisadores}

A identificação das fases cristalinas dos catalisadores foi realizada por difração de raios $\mathrm{X}$ em difratômetro modelo D8 Advance, Bruker, com uma fonte de cobre, radiação $\mathrm{CuK} \alpha$, com varredura de $0,24^{\circ} / \mathrm{min}, 40 \mathrm{kV}$ e $50 \mathrm{~mA}$, a varredura $2 \theta$ foi variada de $5^{\circ}$ a $85^{\circ}$.

Para avaliar os sítios ácidos presentes nas zeólitas, em quantidade e força, foram realizados testes de dessorção à temperatura programada (DTP) utilizando-se o equipamento ChemBet 3000 da Quantachrome. Anteriormente à saturação de amônia foi realizado a degaseificação da amostra. A saturação por amônia foi realizada a $100^{\circ} \mathrm{C}$ durante $1 \mathrm{~h}$, com mistura gasosa de 5\% de amônia em nitrogênio. Em seguida foi realizada a uma purga para a remoção a amônia fisisssorvida.

Para a dessorção foi realizada uma rampa de aquecimento de $10^{\circ} \mathrm{C} / \mathrm{min}$ até $700^{\circ} \mathrm{C}$ permanecendo nesta temperatura por mais $30 \mathrm{~min}$. A quantificação foi feita através da integração da área da curva do equipamento.

A determinação da razão entre as quantidades de átomos de silício e de alumínio ( $\mathrm{Si} / \mathrm{Al}$ ) foi realizada a análise por ressonância magnética nuclear RMN, esta em equipamento Mercury Plus 300, da Varian, equipado com a sonda para a análise em sólidos CP/MAS 7 mm A operação ocorreu a 59,61 MHz para o núcleo 29Si.

\section{RESULTADOS E DISCUSSÕES}

\section{Caracterização dos Catalisadores}

A análise de difração de raios-X (Figura 1) mostrou que a zeólita NaY, apresenta a cristalinidade característica de sua estrutura, conforme o mostrado por Treacy e Higgins (2001). 


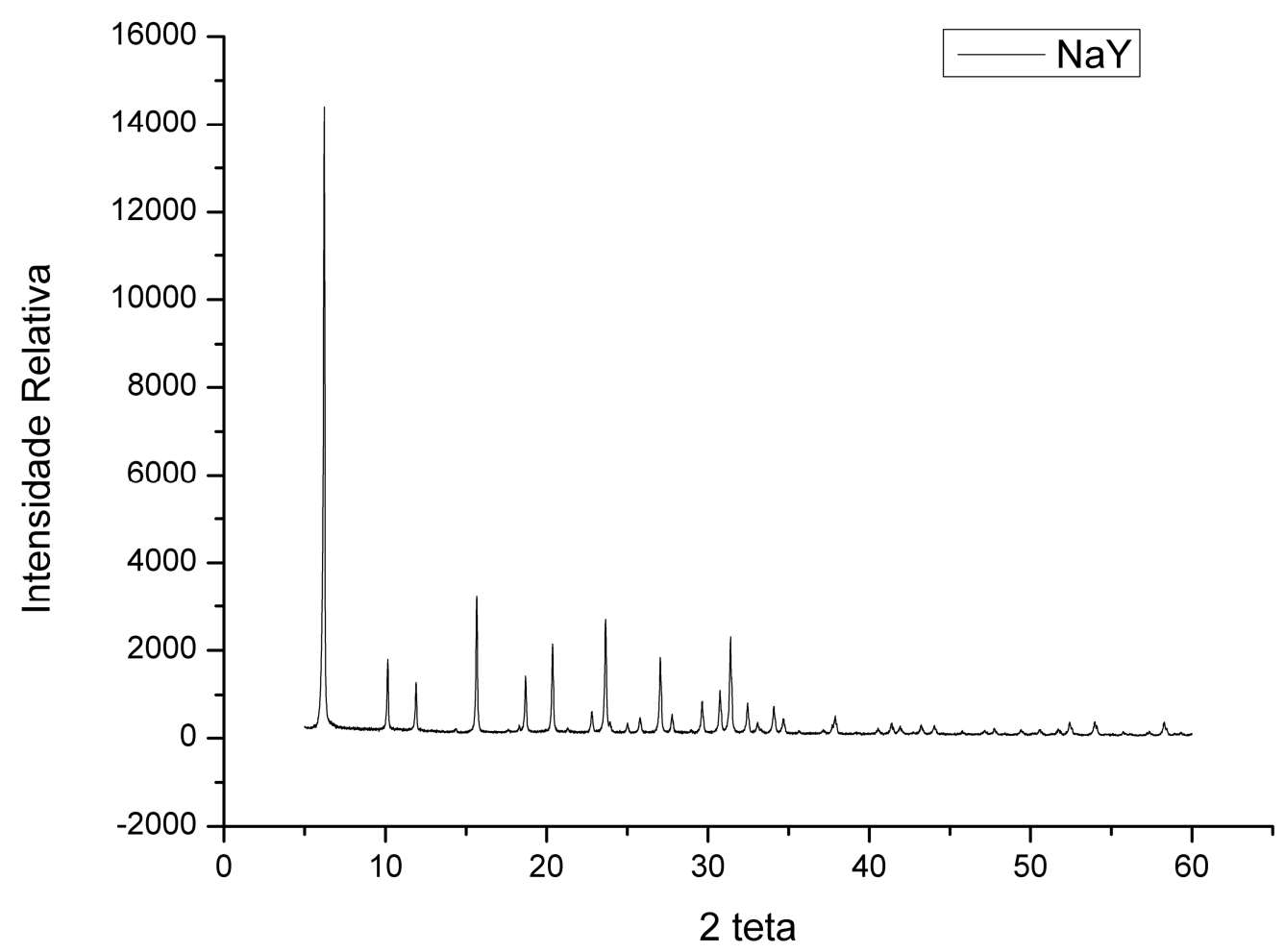

Figura 1 - Difratograma de raios-X do catalisador NaY.

As análises de ressonância magnética de ${ }^{29} \mathrm{Si} \mathrm{e}{ }^{27} \mathrm{Al}$ mostraram as diferentes razões entre o silício e o alumínio que se situam na rede estrutural dos catalisadores utilizados. No caso da zeólita $\mathrm{NaY}$, o espectro de ${ }^{29} \mathrm{Si}$ mostrou que este material possui silício da estrutura coordenado com um, dois, três e quatro átomos de alumínio, conforme a Figura 2, onde também é possível observar o pico dos alumínios tetraédricos no espectro ${ }^{27} \mathrm{Al}$. A ausência de pico referente ao alumínio octaédrico indica a inexistência de alumínio fora da rede cristalina. Através da intensidade dos picos do espectro de ressonância de ${ }^{29} \mathrm{Si}$, encontrou-se a razão silício/alumínio estrutural de 1,55, como o observado na literatura para a mesma zeólita (HASEGAWA et al., 2002). 


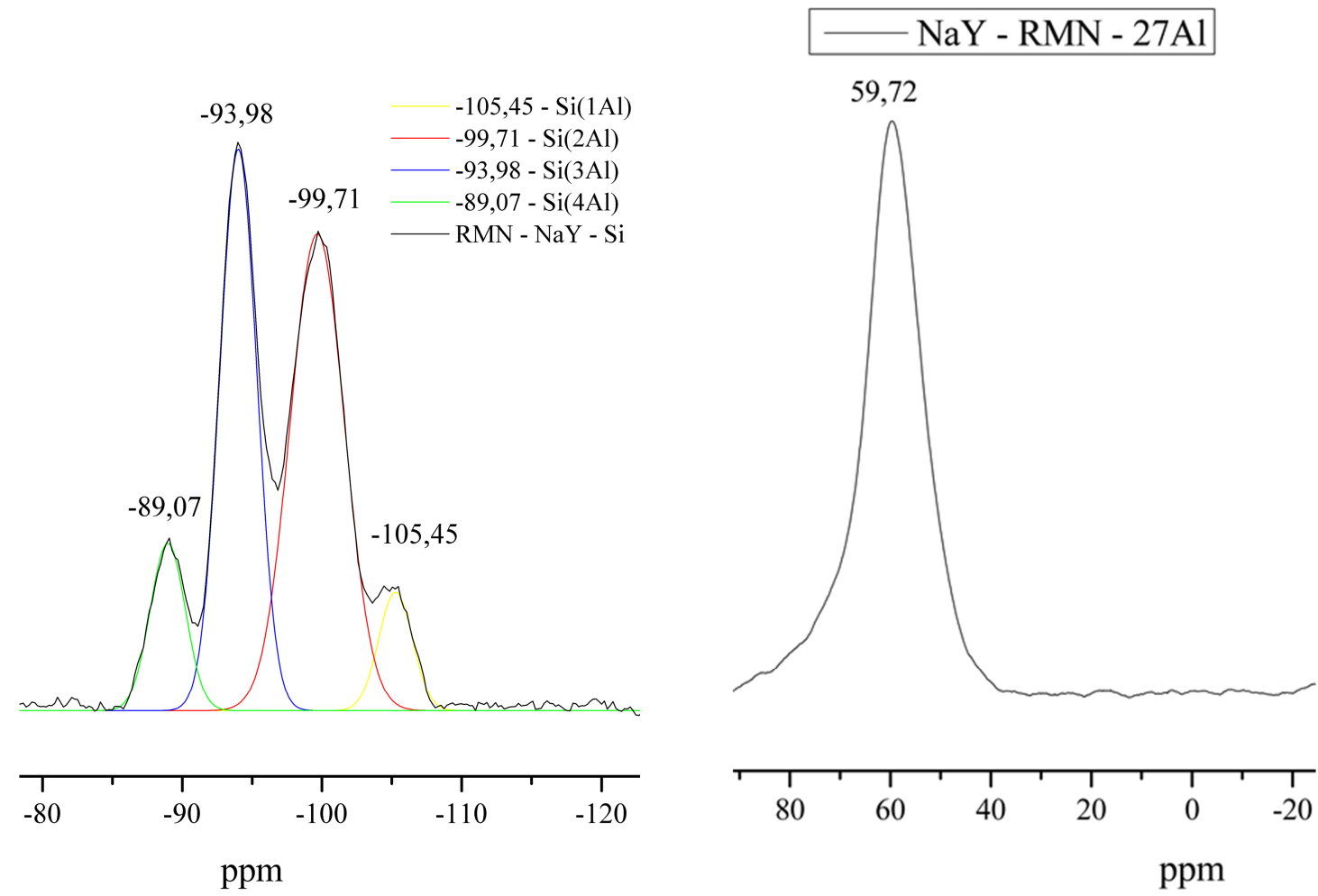

Figura 2 - Espectro de ressonância magnética nuclear ${ }^{29} \mathrm{Si} \mathrm{e}{ }^{27} \mathrm{Al}-\mathrm{NaY}$

A zeólita USY, que é a zeólita Y desaluminizada para melhorar a sua estabilidade, não apresentou em seu espectro o pico de silícios coordenados com quatro alumínios, conforme a Figura 3, onde também é possível observar o pico de alumínio tetraédrico $(60,58 \mathrm{ppm})$ da estrutura cristalina, além de um pico octaédrico (-0,31 ppm), em pequena quantidade, indicando resíduo do processo de desaluminização. Através da intensidade dos picos do espectro de ressonância de ${ }^{29} \mathrm{Si}$, encontrou-se a razão silício/alumínio estrutural de 2,63. A razão encontrada para essa zeólita foi muito baixa se comparada às da literatura. Tal razão pode ser explicada por deficiências no processo de ultraestabilização, indicando que pouco alumínio foi removido. O que pode gerar pouca diferença de acidez entre os materiais, como foi observado pela DTP (Figuras 4 e 5). 

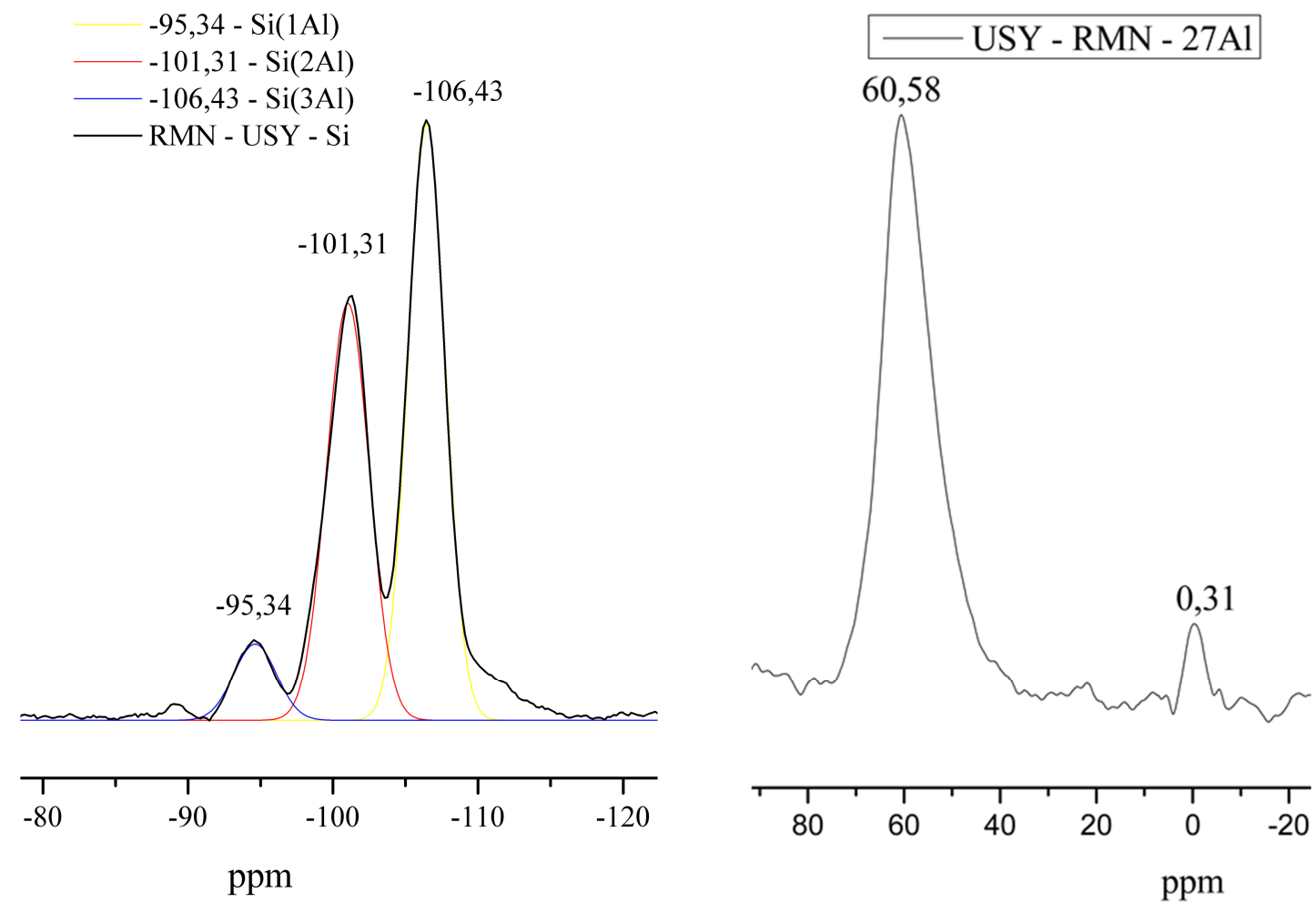

Figura 3 - Espectro de ressonância magnética nuclear ${ }^{29} \mathrm{Si}$ e ${ }^{27} \mathrm{Al}$ - USY

As zeólitas USY e NaY apresentaram acidez como o esperado. Na Figura 4 é possível se observar a acidez da zeólita NaY. A análise mostrou um pico de dessorção de amônia em $239.4^{\circ} \mathrm{C}$, porém através da deconvolução, observa-se a presença de dois picos. $\mathrm{O}$ primeiro a $231.9^{\circ} \mathrm{C}$ indica a presença de sítios de acidez fraca, por dessorverem a amônia a uma temperatura menor. $\mathrm{O}$ segundo a $271.18{ }^{\circ} \mathrm{C}$ indica a presença de sítios de acidez moderada, por necessitarem de uma temperatura maior para dessorverem a amônia.

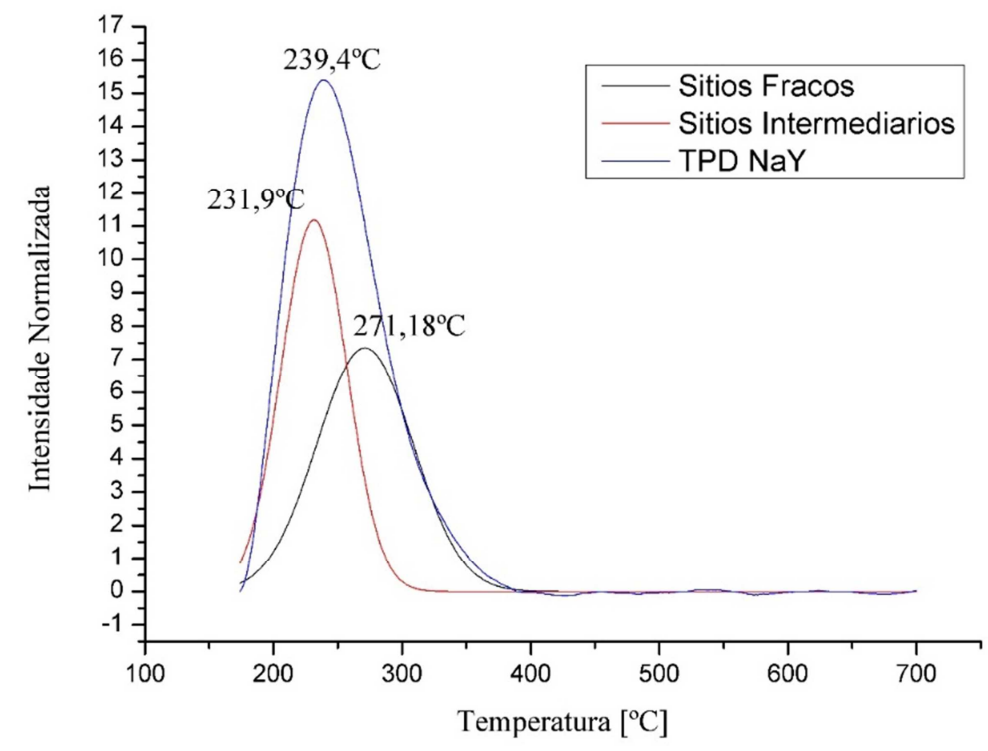

Figura 4 - Dessorção à temperatura programada do catalisador $\mathrm{NaY}$

Revista Brasileira de Energias Renováveis, v. 3, p.268- 282, 2014 
A Figura 5 indica a análise de DTP para o catalisador USY. Aparentemente não se observa uma grande mudança na acidez do material em relação a zeólita anterior, tem-se um pico em $245,5^{\circ} \mathrm{C}$, mostrando um pequeno deslocamento na temperatura de dessorção, além de um alongamento desse pico até a região de $550^{\circ} \mathrm{C}$. Porém através da dessorção, observa-se a presença de três picos de dessorção de amônia. O primeiro a $233,85^{\circ} \mathrm{C}$ indica a presença de sítios fracos, o segundo a $282,15^{\circ} \mathrm{C}$ indica a presença de sítios moderados, como o encontrado na zeólita $\mathrm{NaY}$. Porém, a análise também revela a presença de picos de acidez forte, esses por terem a maior temperatura de dessorção encontrada, $376,35{ }^{\circ} \mathrm{C}$.

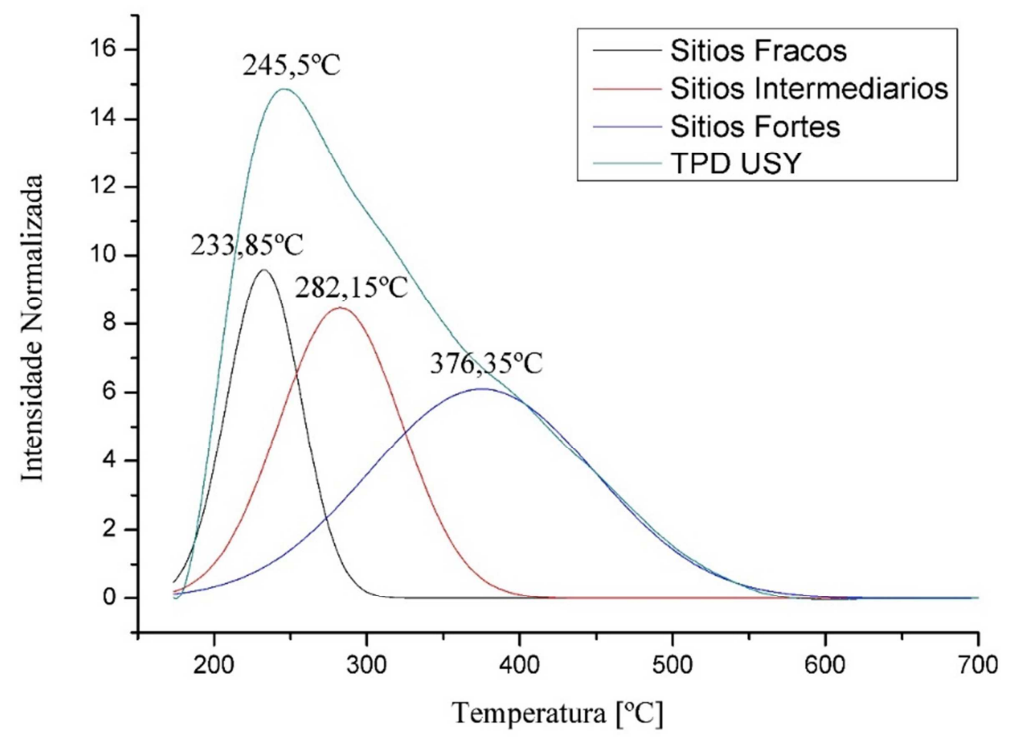

Figura 5 - Dessorção à temperatura programada do catalisador USY

A Tabela 1 mostra os valores de acidez dessas zeólitas, estes obtidos pela integração das curvas das Figuras 4 e 5, que representam os resultados das análises de DTP.

Tabela 1 - Valores de Acidez para USY, NaY e HY

\begin{tabular}{|c|c|c|c|c|c|}
\hline & & \multicolumn{3}{|l|}{ Sítios } \\
\hline & & Zeólita & Fracos & Médios & Fortes \\
\hline \multirow{2}{*}{ Acidez } & 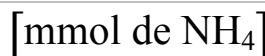 & $\mathrm{NaY}$ & 0,2966 & 0,2878 & \\
\hline & $\mathrm{g}_{\text {cat }}$ & USY & 0,3254 & 0,2469 & 0,1684 \\
\hline
\end{tabular}

A zeólita USY apresentou um maior valor de acidez que a NaY, isso se dá devido ao processo de ultraestabilização ao qual a zeólita USY é submetida. Há duas contribuições para o aumento da acidez, a principal delas é a substituição no cátion de compensação $\mathrm{Na}^{+}$pelo $\mathrm{H}^{+}$ 
através da troca iônica, a outra é o fato de que o processo de desaluminização deixa os átomos de alumínio, gerador dos sítios ácidos, mais distantes entre si. Apesar de em menor quantidade do que na zeólita de partida isso aumenta a força ácida. Essas duas contribuições podem ter ocasionado o deslocamento do pico de temperatura da análise DTP entre a NaY e a USY, assim como o surgimento de um alongamento no pico da segunda.

\section{Produtos do Craqueamento}

A tabela 4 apresenta o perfil de distribuição de produtos para 30 min de reação, agrupados pelas quantidades de carbono dos hidrocarbonetos e dos grupos oxigenados, assim como a concentração de dióxido de carbono e de água. Os hidrocarbonetos com de 1 a 4 átomos de carbono compõem a fração gasosa, já a fração de hidrocarbonetos leves, como gasolina, têm de 5 a 8 átomos carbono e a fração de hidrocarbonetos pesados, como querosene e diesel, têm de 9 a 18 átomos de carbono.

Os grupos oxigenados são representados pelos ácidos presentes no óleo, estes que são os que compõem os triglicerídeos. Já os ácidos fragmentados são as moléculas orgânicas com grupamentos ácidos com cadeia carbônica menor que os ácidos do óleo e que não estavam presentes no mesmo. O grupo R-O representa radicais oxigenados, originados da hidrodesoxigenação parcial dos ácidos. O valor da seletividade representa a razão entre a quantidade em massa de hidrocarbonetos (Hi) e a quantidade de oxigenados (Ox) produzidos.

Através da Tabela 4 se observa que a zeólita USY produziu mais hidrocarbonetos, na faixa dos gasosos e dos leves, do que a NaY. Resultado que pode ser atribuído à maior acidez da zeólita ultraestabilizada, esta característica proporciona uma maior capacidade de fragmentação das moléculas.

A zeólita $\mathrm{NaY}$ foi a que apresentou a maior seletividade em relação aos hidrocarbonetos líquidos, onde encontrou-se uma grande quantidade de hidrocarbonetos de cadeia longa, o que pode ser atribuído à sua menor acidez, o que indica que com uma menor acidez a capacidade de fragmentação é também menor. Desses hidrocarbonetos líquidos observados no produto da NaY, podem-se observar na Figura 5, os com cadeia de 16 e 18 carbonos, que correspondem aos ácidos graxos do óleo que sofreram hidrodesoxigenação. Do mesmo modo se observam os hidrocarbonetos com 15 e 17 carbonos, que correspondem aos hidrocarbonetos que sofreram descarboxilação.

Revista Brasileira de Energias Renováveis, v. 3, p.268- 282, 2014 
Tabela 4 - Distribuição de produtos do craqueamento.

\begin{tabular}{|c|c|c|c|}
\hline \multicolumn{2}{|l|}{ Catalisador } & USY & $\mathrm{NaY}$ \\
\hline Acidez & {$\left[\mathrm{mmol} \mathrm{NH} 3 / \mathrm{g}_{\text {cat }}\right]$} & 0,74 & 0,58 \\
\hline \multirow{3}{*}{ Hidrocarbonetos $[\% ; \mathrm{m} / \mathrm{m}]$} & $\mathrm{C}_{1}-\mathrm{C}_{4}$ & 45,28 & 23,15 \\
\hline & $\mathrm{C}_{5}-\mathrm{C}_{8}$ & 21,73 & 9,25 \\
\hline & $\mathrm{C}_{9}-\mathrm{C}_{18}$ & 14,21 & 31,39 \\
\hline \multirow{5}{*}{ Oxigenados $[\% ; \mathrm{m} / \mathrm{m}]$} & Ácidos do Óleo & 3,54 & 1,97 \\
\hline & Ácidos Orgânicos & 0,30 & 2,56 \\
\hline & $\mathrm{R}-\mathrm{O}$ & 0,00 & 7,37 \\
\hline & $\mathrm{CO}_{2}$ & 5,40 & 10,35 \\
\hline & $\mathrm{H}_{2} \mathrm{O}$ & 9,54 & 13,96 \\
\hline Seletividade & $\mathrm{Hi} / \mathrm{Ox}$ & 21,12 & 5,36 \\
\hline
\end{tabular}

A seletividade mostra a grande diferença na quantidade de hidrocarbonetos produzidos entre os dois catalisadores utilizados, onde a zeólita USY foi mais seletiva a hidrocarbonetos. 


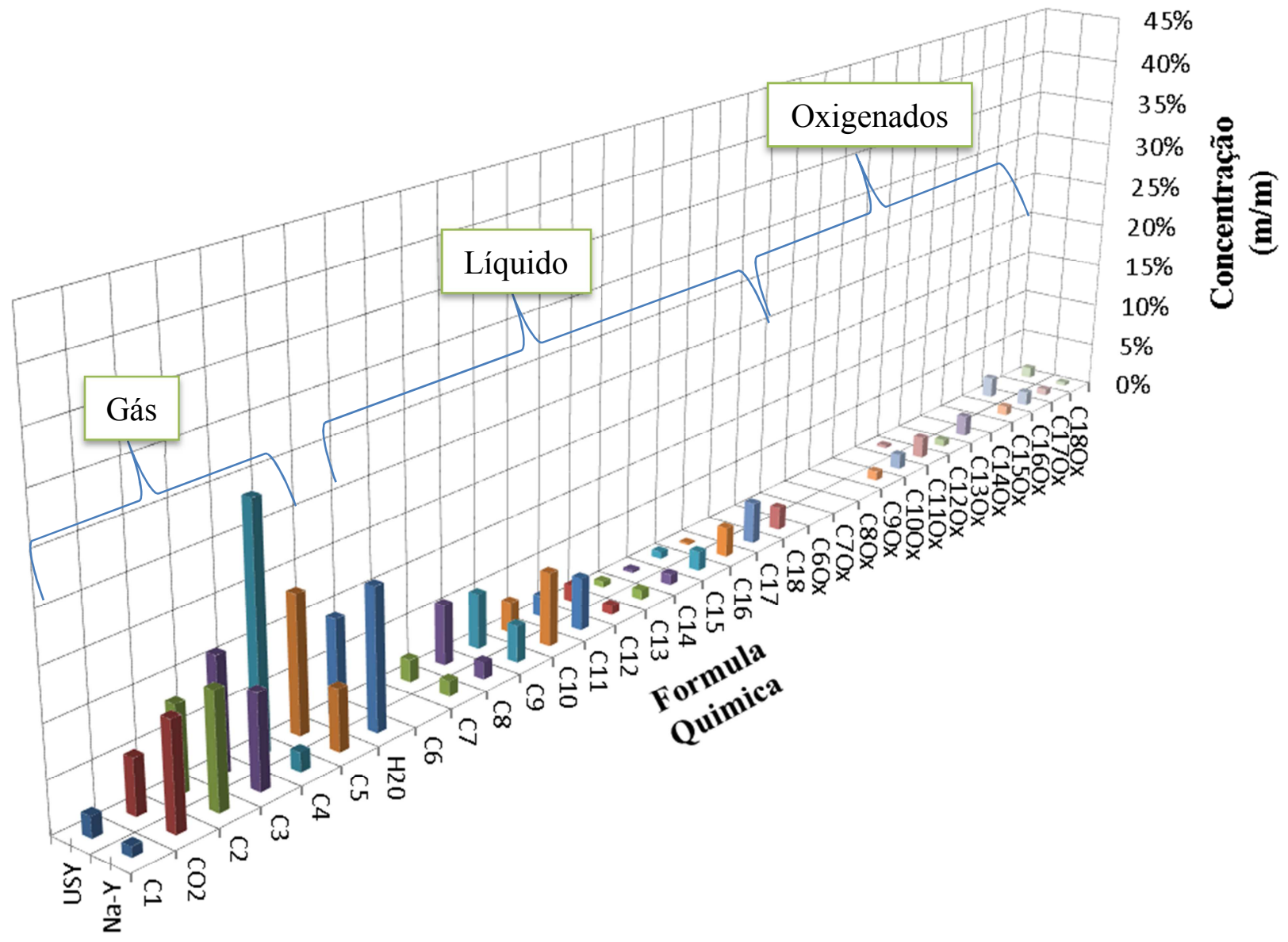

Figura 5 - Distribuição dos produtos por número de átomos de carbono

Em relação aos compostos oxigenados, observa-se que a quantidade de ácidos do óleo foi maior no produto do craqueamento com USY, quantidade estas representadas pelos ácidos, oleico (C180x), linoleico (C180x) e palmítico (C16Ox), na Figura 5. Já a quantidade de ácidos orgânicos foi maior para $\mathrm{NaY}$, mostrando que esse material foi capaz de fragmentar as cadeias carbônicas sem desoxigená-las, produzindo ácidos graxos de cadeias menores, como observado na Figura 5. A zeólita NaY produziu 7,37 \% de R-O de cadeia longa.

Observando-se a relação entre a quantidade de $\mathrm{CO}_{2}$ e $\mathrm{H}_{2} \mathrm{O}$ produzidos, ambos os catalisadores tiveram preferência pelo processo de hidrodesoxigenação dos ácidos graxos, porém, a quantidade de dióxido indica que o processo de descarboxilação também aconteceu. A quantidade de $\mathrm{H}_{2} \mathrm{O}$ produzida pela $\mathrm{NaY}$ teve contribuição também da hidrodesoxigenação parcial.

O produto R-O encontrado no craqueamento com $\mathrm{NaY}$, foi identificado pelo espectro de RMN como sendo álcoois de cadeia longa. A formação desses compostos no produto está

Revista Brasileira de Energias Renováveis, v. 3, p.268- 282, 2014 
intimamente ligada ao processo de hidrodesoxigenação parcial das moléculas orgânicas oxigenadas, ou ainda ao processo de fragmentação dos triglicerídeos, que são compostos oxigenados. Através da tabela 5, observa-se os compostos R-O, produzidos pelo craqueamento com NaY. Os dois produtos com a maior cadeia carbônica (Octanol, 2fenilmetileno- e 3-Octadecanol) podem ter origem de processos complexos de oligomerização térmica comuns em processos de craqueamento.

Tabela 5 - Distribuição de compostos R-O no produto do craqueamento com NaY

\begin{tabular}{|l|l|l|}
\hline Quantidade & Composto & Formula Química \\
\hline $1,01 \%$ & 2-Decanol & $\mathrm{C}_{10} \mathrm{H}_{22} \mathrm{O}$ \\
\hline $1,12 \%$ & 2-Undecanol & $\mathrm{C}_{11} \mathrm{H}_{24} \mathrm{O}$ \\
\hline $0,62 \%$ & $2,4-D e c a d i e n-1-o l$ & $\mathrm{C}_{10} \mathrm{H}_{18} \mathrm{O}$ \\
\hline $0,80 \%$ & 2-Undecanol & $\mathrm{C}_{11} \mathrm{H}_{24} \mathrm{O}$ \\
\hline $2,36 \%$ & 1-Tridecanol & $\mathrm{C}_{13} \mathrm{H}_{28} \mathrm{O}$ \\
\hline $1,07 \%$ & Octanol, 2-(fenilmetileno)- & $\mathrm{C}_{15} \mathrm{H}_{20} \mathrm{O}$ \\
\hline $0,39 \%$ & 3-Octadecanol & $\mathrm{C}_{18} \mathrm{H}_{36} \mathrm{O}$ \\
\hline
\end{tabular}

Os ácidos orgânicos fragmentados encontrados no produto final estão relacionados na tabela 6. Observam-se os ácidos orgânicos diferentes dos encontrados nos triglicerídeos que compõem o óleo de soja. A zeólita NaY produziu mais ácidos fragmentados que a USY. Isso pode indicar que a maior acidez é capaz de desoxigenar mais os compostos, ou ainda que a menor acidez da $\mathrm{NaY}$ tenha fragmentado apenas parcialmente os compostos orgânicos, o que também se observou na baixa produção de gases no craqueamento com esse material.

Tabela 6 - Distribuição ácidos fragmentados produto do craqueamento com Na-Y

\begin{tabular}{|l|l|l|l|}
\hline Catalisador & Quantidade & Produto & Fórmula \\
\hline \multirow{2}{*}{$\mathrm{NaY}$} & $1,03 \%$ & Ácido 2-Nonenoico & $\mathrm{C}_{9} \mathrm{H}_{16} \mathrm{O}_{2}$ \\
\cline { 2 - 4 } & $1,18 \%$ & Ácido Undecilenico & $\mathrm{C}_{11} \mathrm{H}_{20} \mathrm{O}_{2}$ \\
\cline { 2 - 4 } & $0,74 \%$ & Ácido Benzeno-undecanoico & $\mathrm{C}_{17} \mathrm{H}_{26} \mathrm{O}_{2}$ \\
\hline USY & $0,35 \%$ & Ácido Decanoico & $\mathrm{C}_{10} \mathrm{H}_{20} \mathrm{O}_{2}$ \\
\hline
\end{tabular}


Os dados da Tabela 7 foram extraídos da Tabela 5 juntando-se as diferentes classes de moléculas orgânicas presentes no produto líquido, independentemente do número de átomos de carbono. Observa-se a presença de diferentes classes de hidrocarbonetos e de compostos oxigenados. Quanto aos hidrocarbonetos, a USY foi mais seletiva a compostos aromáticos e a NaY mais seletiva a compostos alifáticos. Isso pode indicar que uma maior acidez favorece o processo de desidrogenação, junto ao craqueamento, tornando um número maior de hidrocarbonetos alifáticos em aromáticos.

Tabela 7 - distribuição das classes de moléculas no produto líquido

\begin{tabular}{|l|l|l|l|l|l|}
\hline Catalisadores & Aromáticos & Cíclicos & Alifáticos & Ácidos & R-O \\
\hline USY & $21,53 \%$ & $0,17 \%$ & $0,74 \%$ & $3,85 \%$ & $0,00 \%$ \\
\hline NaY & $15,84 \%$ & $3,20 \%$ & $15,60 \%$ & $4,53 \%$ & $7,37 \%$ \\
\hline
\end{tabular}

\section{CONCLUSÃO}

Os resultados de caracterização das zeólitas NaY e USY mostraram que a diferença entre a razão $\mathrm{Si} / \mathrm{Al}$ estrutural da zeólitas empregadas levou a uma diferença na distribuição e força ácida das mesmas. Tal diferença refletiu no desempenho do material, evidenciada pela diferença nos produtos obtidos. Os resultados mostraram também a viabilidade de se produzir hidrocarbonetos na faixa dos combustíveis líquidos e gasosos, além de insumos petroquímicos, empregando-se de óleos de baixo custo ou não refinado.

\section{AGRADECIMENTO}

Agradecimento à CAPES, pela concessão de bolsa de estudo à Cassio Henrique Zandonai

\section{REFERÊNCIAS}

CHEN, Y.; WANG, C.; LU, W.; YANG, Z. Study of the co-deoxy-liquefaction of biomass and vegetable oil for hydrocarbon oil production. Bioresource technology, v. 101, n. 12, p. 4600-7, 2010. Elsevier Ltd. 
DUPAIN, X.; COSTA, D. J.; SCHAVERIEN, C. J.; MAKKEE, M.; MOULIJN, J. Cracking of a rapeseed vegetable oil under realistic FCC conditions. App. Cat. B: Env., v. 72, n. 1-2, p. 44-61, 2007.

HARTMAN, L.; LAGO, R. C. A. Rapid preparation of fatty acid methyl from lipids. Laboratory Practice, v. 22, n. 3, p. 475-473, 1973.

HASEGAWA, Y.; TANAKA, T.; WATANABE, K. Separation of CO2-CH4 and CO2-N2 systems using ion-exchanged FAU-type zeolite membranes with different Si/Al ratios. Korean Journal of Chemical Engineering, v. 19, n. 2, p. 309-313, 2002.

MELERO, J. A.; ClAVERO, M. M.; CALlEJA, G.; et al. Production of Biofuels via the Catalytic Cracking of Mixtures of Crude Vegetable Oils and Nonedible Animal Fats with Vacuum Gas Oil. Energy \& Fuels, v. 24, n. 1, p. 707-717, 2010.

TIAN, H.; LI, C.; YANG, C.; SHAN, H. Alternative Processing Technology for Converting Vegetable Oils and Animal Fats to Clean Fuels and Light Olefins. Chinese J. of Chem. Eng., v. 16, n. 3, p. 394-400, 2008.

TREACY, .M.J.; HIGGINS, J. B. Collection of Simulated XRD Powder Patterns for Zeolites. Amsterdam: Elsevier, 2001.

TWAIQ, F. A.; ZABIDI, N. A. M.; BHATIA, S. Catalytic Conversion of Palm Oil to Hydrocarbons: Performance of Various Zeolite Catalysts. Industrial \& Engineering Chemistry Research, v. 38, n. 9, p. 3230-3237, 1999.

TWAIQ, F.; MOHAMAD, A. R.; BHATIA, S. Performance of composite catalysts in palm oil cracking for the production of liquid fuels and chemicals. Fuel Proc. Tech., v. 85, n. 11, p. 1283-1300, 2004.

YANG, Y.; WANG, Q.; ZHANG, X.; WANG, L.; LI, G. Hydrotreating of C18 fatty acids to hydrocarbons on sulphided NiW/SiO2-A12O3. Fuel Proc. Tech., v. 116, p. 165-174, 2013. Elsevier B.V. 